\title{
Pulmonary Alveolar Microlithiasis A commonly misdiagnosed rare entity
}

*Alkesh Khurana, ${ }^{1}$ Rajesh Malik, ${ }^{2}$ Jitendra Sharma, ${ }^{2}$ Ujjawal Khurana, ${ }^{3}$ Deepti Joshi, ${ }^{3}$ Abhishek Goyal ${ }^{1}$

$$
\text { تكون الحصيّات الدقيقة في حويصلاكت الرئة الهوائية }
$$

ألكيش كورانا، راجيش ماليك، جيتندرا شارما، أوجوال كورانا، ديبتي جوشي، ابيشيك جويال

ABSTRACT: Pulmonary alveolar microlithiasis (PAM) is an uncommon entity which can pose a diagnostic challenge. We report a 45-year-old female who was referred to the All India Institute of Medical Sciences, Bhopal, India, in 2017 with a two-year history of progressively worsening dyspnoea and dry coughing. She had been previously diagnosed with pulmonary tuberculosis elsewhere and prescribed antitubercular therapy; however, there was little improvement in her symptoms. Following referral, the patient was diagnosed with PAM based on high-resolution computed tomography findings and the abundance of lamellar microliths in a bronchoalveolar lavage sample. She was subsequently managed symptomatically and enrolled in a rehabilitation programme.

Keywords: Calcinosis; Pulmonary Alveolar Microlithiasis; Pulmonary Tuberculosis; Misdiagnosis; Case Report; India.

$$
\begin{aligned}
& \text { الملخص: يعتبر تكون الحصيّات الدقيقة في حويصلات الرئة الهوائية من الحالات المرضية الغير شائعة والتي تمثل في الغالب البـات تحدئا }
\end{aligned}
$$

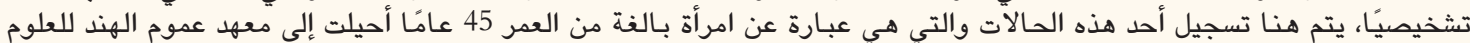

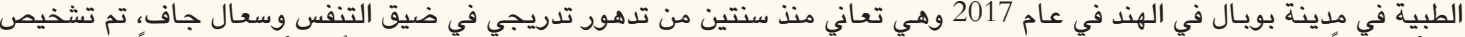

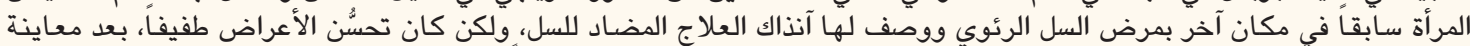

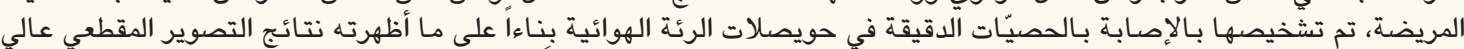

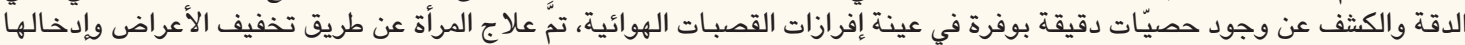

$$
\begin{aligned}
& \text { في برنامج إعادة تأهيل. } \\
& \text { الكلمات المفتاحية: التكلُّ؛ تكون الحصيّات الدقيقة في حويصلات الرئة الهوائية؛ السل الرئوي؛ خطأ التشخيص الطبي؛ تقرير حالة؛ الهند. }
\end{aligned}
$$

$\mathrm{P}$ ULMONARY ALVEOLAR MICROLITHIASIS (PAM) is a rare pathological entity not commonly encountered in routine clinical practice. ${ }^{1}$ Affected patients are often initially misdiagnosed and may undergo unnecessary treatment, such as antitubercular therapy in tuberculosis-endemic countries. ${ }^{2}$ As such, clinicians, radiologists and pathologists should be made aware of this entity so as to ensure a correct diagnosis.

\section{Case Report}

A 45-year-old female was referred to the Outpatient Pulmonology Department of the All India Institute of Medical Sciences, Bhopal, India, in 2017 with progressively worsening dyspnoea and dry coughing over the past two years. There was no history of fever, anorexia or weight loss. She had previously undergone chest radiography at other centres and been diagnosed with pulmonary tuberculosis, for which she was prescribed antitubercular therapy. However, as there was very little improvement in her symptoms, she was subsequently referred to the All India Institute of Medical
Sciences. At referral, a chest X-ray of the patient showed a bilateral dense micronodular pattern with fine reticulation predominantly at the bases, with a 'sandstorm'-like appearance [Figure 1]. Similar findings were noted in serial radiographs from the previous year. Her total leukocyte count was $9,000 / \mathrm{mm}^{3}$, with a differential cell count of 56\% neutrophils, 39\% lymphocytes, $4 \%$ monocytes and $1 \%$ eosinophils. Her haemoglobin levels were $13.1 \mathrm{~g} / \mathrm{dL}$ and there was no history of haemoptysis since the onset of the illness. Other investigations, namely serum electrolytes (i.e. sodium, potassium, calcium, phosphorus and magnesium), renal function and liver function tests, were all within normal limits.

Pulse oximetry indicated an oxygen saturation of $94 \%$ in room air. Pulmonary function tests yielded a classical restrictive pattern with a normal forced expiratory volume (FEV1)/forced vital capacity (FVC) ratio and reduced FEV1 and FVC measurements (percent predicted values of $101 \%, 49 \%$ and $49 \%$, respectively). An electrocardiogram and two-dimensional echocardiograph were essentially normal, with 


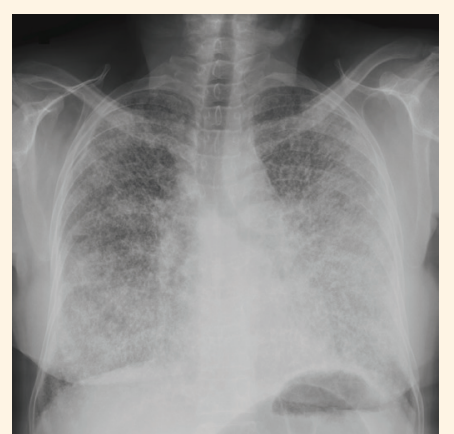

Figure 1: Chest X-ray of a 45-year-old female showing a bilateral dense micronodular pattern with fine reticulation.

mildly elevated pulmonary artery pressure and no evidence of valvular heart disease. A high-resolution computed tomography (CT) scan revealed extensive dense interlobular and intralobular septal thickening of the parenchymal window and dense microcalcification with a predominantly subpleural and peribronchial distribution, suggestive of pulmonary alveolar microlithiasis [Figure 2].

The next day, the patient underwent flexible bronchoscopy. Bronchoalveolar lavage (BAL) smears showed microliths, alveolar macrophages, ciliated columnar epithelial cells and multinucleate macrophage giant cells [Figure 3]. According to a differential cell count, the BAL sample consisted predominantly of alveolar macrophages (91\%). The microliths were spherical lamellate refractile fragile bodies which were predominantly extracellular and varied from $100-120 \mu \mathrm{m}$ in size. There were between 2-12 nuclei in the multinucleate giant cells. A transbronchial lung biopsy (TBLB) showed sheets

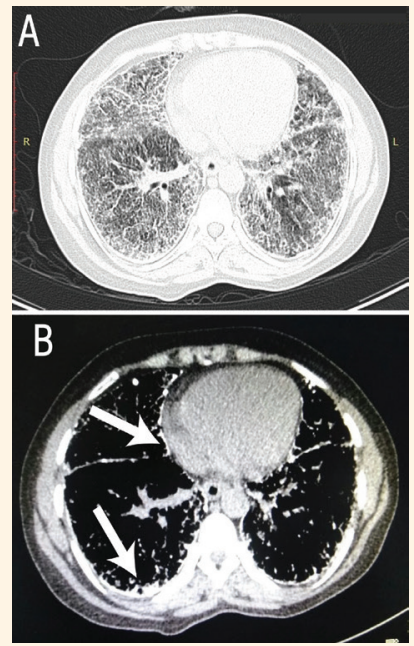

Figure 2: Computed tomography of the (A) lung window of a 45-year-old female showing diffuse dense interlobular and intralobular septal thickening with patchy ground glass opacities and (B) the mediastinal window showing diffuse microcalcification in both lungs with a subpleural and peribronchial distribution. Pleural and pericardial calcification (arrows) is also present.

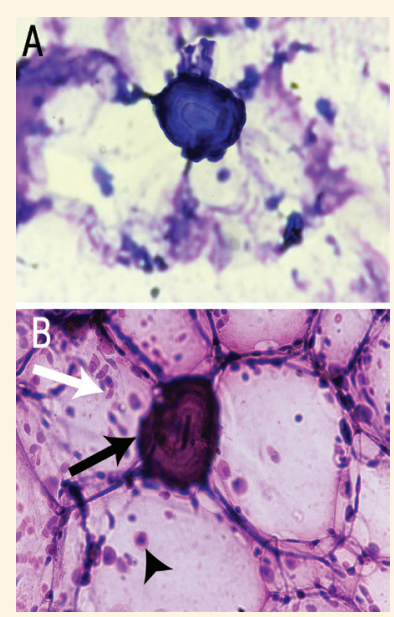

Figure 3: A: Wright Giemsa stain at x400 magnification showing spherical concentrically lamellate refractile microliths*. B: Papanicolaou stain of a bronchoalveolar lavage sample at x400 magnification showing a microlith (arrowhead), alveolar macrophage (black arrow) and ciliated columnar epithelial cell (white arrow).

"The fine focusing of these bodies makes the background cells appear out of focus.

of foamy macrophages containing periodic acid-Schiff (PAS)-positive material in the subepithelium; however, no microliths were visible. The patient was subsequently diagnosed with PAM. Since a lung transplant was not feasible, she was managed symptomatically and enrolled in a rehabilitation programme. Her family was also screened for the disease using chest X-rays; however, no other cases were identified.

\section{Discussion}

PAM is a rare disease characterised by the widespread accumulation of minute calculi known as microliths in the lung parenchyma. ${ }^{1}$ The most likely aetiopathogenesis of the disease is a mutation in the solute carrier family 34 member 2 (SLC34A2) gene, which leads to the ineffective uptake of phosphate from the alveoli and, therefore, the accumulation of calcium phosphate crystals. ${ }^{3}$ In the most comprehensive review of this entity to date, Castellana et al. analysed 1,022 PAM cases reported worldwide and noted that the disease had a slight male preponderance and most patients were in their second or third decade of life. ${ }^{1}$ A total of 80 patients were of Indian origin. A positive family history was reported in $37 \%$ of cases. ${ }^{1}$ In the current case, the patient was an Indian female in her fifth decade of life and had no family history of PAM or a similar illness.

A diagnosis of PAM usually depends on the identification of various radiological and histopathological features. In particular, the radiographical appearance of the patient's lungs corresponds to the increasing severity of the disease. ${ }^{4}$ During the first stage, the radio- 
logical findings are precalcific, although this is identified very rarely. In the second stage, the lungs have a typical 'sandy' appearance, with scattered microliths and a delineated cardiac border. ${ }^{4}$ The density of the microliths then increases to obscure the cardiac borders in the third phase, before involving the pleura in the fourth phase, as noted in the current case. ${ }^{4}$ Despite these typical radiological features, it is not uncommon for patients to be misdiagnosed with tuberculosis, as in the present case, particularly in endemic areas. ${ }^{2}$ Despite this, the coexistence of tuberculosis and PAM is rare. ${ }^{1}$ Other diseases associated with a miliary dissemination include sarcoidosis, pneumoconiosis, haemosiderosis, amyloidosis and mycosis. However, while the radiological appearance of calcifications are more intense in PAM cases, the symptoms of these other differential diagnoses are usually more severe.

In order to confirm the diagnosis, a lung biopsy is required to demonstrate the presence of characteristic PAS-positive concentric calcareous lamellae around a central nucleus. ${ }^{1}$ The microliths should be differentiated from psammoma bodies, indicative of a malignant condition; these are similar in structure but occur as part of the epithelial cell group or as small tissue fragments. ${ }^{5}$ While the analysis of BAL samples is often inconclusive, the cytological findings in the current case were very characteristic of PAM, demonstrating both microliths and multinucleate giant cells. ${ }^{6,7}$ However, the presence of microliths in the BAL fluid rather than in the TBLB specimen was unusual, particularly as the latter technique is usually more sensitive for diffuse lung disease. ${ }^{8}$ This may have been because of the blind nature of the technique. In general, less than $50 \%$ of PAM cases have positive TBLB findings. ${ }^{9}$ However, pulmonary function tests may have a supportive role by revealing a restrictive pattern, as seen in the present case. ${ }^{10}$

Once diagnosed, the course of the illness is variable and can either remain stable or become progressively worse, resulting in cor pulmonale. ${ }^{11}$ However, since the onset is insidious and the clinical course is generally quite slow, it can be difficult to definitively establish the onset of the disease. Furthermore, since the $S L C$ $34 A 2$ gene is expressed in certain extrapulmonary tissues-including the testicles, kidneys, pancreas, intestines, breasts, ovaries, liver and prostate-some patients may also have extrapulmonary symptoms, such as infertility, azoospermia, haematuria and gallstones. ${ }^{11,12}$ Currently, no medical or genetic therapy is yet available, with chelating agents and therapeutic lung lavage reported to be ineffective. ${ }^{10}$ To date, lung transplantation is the only accepted treatment, with survival up to 15 years reported without recurrence. ${ }^{13}$

\section{Conclusion}

Despite its rarity, there is a need to increase the index of suspicion of PAM among clinicians, radiologists and pathologists in order to avoid misdiagnosis and unnecessary treatment. This case emphasises the combined role of high-resolution CT and BAL analysis in the diagnosis, thus avoiding the need for invasive procedures such as an open lung biopsy.

\section{References}

1. Castellana G, Castellana G, Gentile M, Castellana R, Resta O. Pulmonary alveolar microlithiasis: Review of the 1022 cases reported worldwide. Eur Respir Rev 2015; 24:607-20. doi: 10.11 83/16000617.0036-2015.

2. Govindaraj V, Manju R, Jaganathan V, Udupa A, Hariprasad V, Saka V. Pulmonary alveolar microlithiasis: A case report. Int J Sci Study 2015; 3:212-15. doi: 10.17354/ijss/2015/190.

3. Corut A, Senyigit A, Ugur SA, Altin S, Ozcelik U, Calisir H, et al. Mutations in SLC34A2 cause pulmonary alveolar microlithiasis and are possibly associated with testicular microlithiasis. Am J Hum Genet 2006; 79:650-6. doi: 10.1086/508263.

4. Castellana G, Castellana R, Fanelli C, Lamorgese V, Florio C. [Pulmonary alveolar microlithiasis: Clinical and radiological course of three cases according to conventional radiology and HRCT - A hypothesis for radiological classification]. Radiol Med 2003; 106:160-8

5. Martínez-Girón R, Martínez-Torre S, Tamargo-Peláez ML, López-Cabanilles MD, Torre-Bayón C. Calcareous concretions and psammoma bodies in sputum smears: Do these similar structures have different clinical significance? Diagn Cytopathol 2014; 42:759-65. doi: 10.1002/dc.23120.

6. Jönsson ÅL, Simonsen U, Hilberg O, Bendstrup E. Pulmonary alveolar microlithiasis: Two case reports and review of the literature. Eur Respir Rev 2012; 21:249-56. doi: 10.1183/09059 180.00009411

7. Monabati A, Ghayumi MA, Kumar PV. Familial pulmonary alveolar microlithiasis diagnosed by bronchoalveolar lavage: A case report. Acta Cytol 2007; 51:80-2. doi: 10.1159/000325688.

8. Casoni GL, Cordeiro CR Jr, Tomassetti S, Romagnoli M, Chilosi M, Cancellieri A, et al. The role of transbronchial biopsy in the diagnosis of diffuse parenchymal lung diseases: Pro. Rev Port Pneumol 2012; 18:57-60. doi: 10.1016/j.rppneu.2011.05.003.

9. Mariotta S, Ricci A, Papale M, De Clementi F, Sposato B, Guidi L, et al. Pulmonary alveolar microlithiasis: Report on 576 cases published in the literature. Sarcoidosis Vasc Diffuse Lung Dis 2004; $21: 173-81$

10. Prakash UB, Barham SS, Rosenow EC 3rd, Brown ML, Payne WS. Pulmonary alveolar microlithiasis: A review including ultrastructural and pulmonary function studies. Mayo Clin Proc 1983; 58:290-300.

11. Kashyap S, Mohapatra PR. Pulmonary alveolar microlithiasis. Lung India 2013; 30:143-7. doi: 10.4103/0970-2113.110424.

12. Kanat F, Teke T, Imecik O. Pulmonary alveolar microlithiasis with epididymal and periurethral calcifications causing obstructive azospermia. Int J Tuberc Lung Dis 2004; 8:1275.

13. Jackson KB, Modry DL, Halenar J, L'abbe J, Winton TL, Lien DC. Single lung transplantation for pulmonary alveolar microlithiasis. J Heart Lung Transplant 2001; 20:226. doi: 10.1016/S10532498(00)00500-3. 